\title{
What is the Background of Fukushima Daiichi Accident?
}

\author{
Japan Nuclear Safety Institute, Toshiro Kitamura
}

\begin{abstract}
Two years after the Fukushima Daiichi Nuclear Accident, power companies are constructing tide embankments, reinforcing emergency power supplies, and implementing other necessary measures that are mainly intended to address the direct causes of the accident. The accident was aptly dubbed "a disaster made in Japan" by the chairperson of the National Diet of Japan Fukushima Nuclear Accident Independent Investigation Commission (NAIIC). The Fukushima Daiichi Nuclear Accident involves unique factors that are deeply rooted in Japanese society. In a sense, the accident is the ultimate outcome of various mistakes that were committed throughout the history of nuclear power development in this country.
\end{abstract}

\section{Background Factors Leading to Fukushima Daiichi Nuclear Accident}

\section{Causes of the Accident}

Gregory B. Jaczko, the former Chairman of the Nuclear Regulatory Commission (NRC), forthrightly pointed out that the Fukushima Daiichi Nuclear Accident resulted from its misguided design and siting. Allison M. Macfarlane, the current Chairman, went on to say that these mistakes had been neglected for years. In addition to their comments, the failure to respond quickly to external warnings must also be noted, especially bearing in mind that the Japan Atomic Power Company (JAPC) avoided severe accidents at the Tokai Daini Nuclear Power Plant thanks to the protective walls that they built in light of these warnings.

Both the national government and the Tokyo Electric Power Company (TEPCO) possessed information on the station blackouts experienced at nuclear power plants in other countries. They were also aware of the possible flooding of vital equipment in the event of a major tsunami. They did not scientifically preclude the occurrence of a tsunami on a scale that may happen once every thousand years. Nevertheless, TEPCO's management prioritized impending management issues over seemly unlikely tsunami hazards.

For some reason, they applied extremely irrational logic. The reason for this must be traced back through the history of nuclear power development in Japan.

DOI : 10.15669/fukushimainsights.Vol.3.43

() 2021 Atomic Energy Society of Japan. All rights reserved.

Originally published in Journal of the Atomic Energy Society of Japan (ISSN 1882-2606), Vol. 55, No. 6, p. 338-341 (2013)

in Japanese. (Japanese version accepted: March 22, 2013) 


\section{Reflecting on History}

Japan's history of nuclear power development can be broken down into three phases, as shown in Figure 1, to identify the factors that led to the Fukushima Daiichi Nuclear Accident.

\section{Phase 1: 1965-1978}

Japan achieved spectacular economic growth due to its large-scale transition from agriculture to industry. During this period, people discovered the wonder of science and technology through developments such as the Shinkansen bullet train coming into service and the Apollo 11 mission being successfully completed. However, the negative consequences of such developments were put off to the next phase.

Politicians, bureaucrats, and industrial circles hastened to adopt nuclear power plants, which had just been put into commercial use in the West. Small-scale light-water reactors developed in the United States boasted a high output and excellent economic performance, but they were not designed for a small country that frequently experiences natural disasters. Japan did not have the capacity to assess the technologies involved, and design modifications are costly and time consuming. As a result, turn-key contracts were signed for the original designs.

Dr. Hideki Yukawa, one of the first members of the Atomic Energy Commission, resigned from his position in disgust at Japan's haste to operate commercial reactors that had been blindly imported from the United States without first verifying their safety while also neglecting to build up the country's own technical capacity based on original studies.

Japanese engineers assigned to work at American reactor manufacturers hungrily learned the relevant technologies. At the same time, they acquired the way of thinking that places great importance on rationality and economy. An increasing number of advocates were stressing the cost advantages of nuclear power. TEPCO's management reasoned that the Fukushima Daiichi Nuclear Power Plant should be sited at a lower altitude to minimize the amount of power consumed for water intake.

Japanese nuclear engineers from various different companies joined forces with JAPC to start operating the first light-water reactor at the Tsuruga Nuclear Power Plant. Soon afterward, TEPCO, the Kansai Electric Power Company (KEPCO), and other partners in this national project stopped loaning out their experts. These companies rushed to construct nuclear power plants in their own regions to begin generating power. However, due to a lack of

Phase $1 \quad$ Phase $2 \quad$ Phase 3

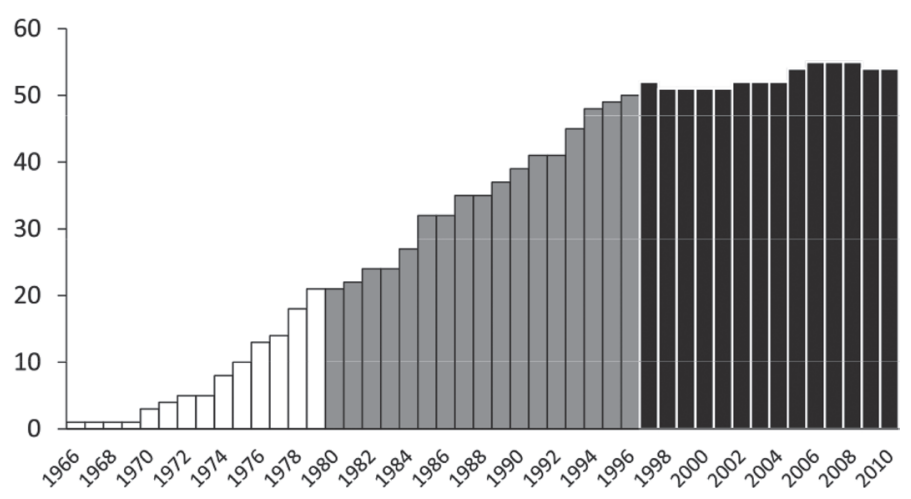

Figure 1 Number of nuclear power reactors in Japan 
suitable knowledge on seismic mechanisms, aside from an understanding of the need for a solid bedrock, the plants were sited based mostly on the local population density, the optimal distance to a major power-consuming area, and other economic factors prioritized.

Once the power operations began, the focus was placed on fixing initial failures while the fundamental problems related to the design and siting of the plants ended up on the back burner. The proportion of nuclear physicists gradually declined in contrast to an increasing proportion of human resources with a background in mechanical engineering, electrical engineering, chemistry, and other such fields. Research on safety systems was deemed highly specialized.

Initially, members of the nuclear power departments at utility companies could engage in unfettered discussions without any constraints inherited from the past. However, once they began to assume the positions of presidents and vice-presidents at these companies, the nuclear power departments began to receive special treatment. In the absence of personnel exchanges with other departments, they began to foster their own corporate culture.

In accordance with national policy, the government left nuclear power plants in the hands of private utility companies, which cooperated with the government in return for generous assistance. Nuclear power development began to increasingly lack transparency for Japanese citizens.

In 1974, power source siting laws were enacted to facilitate the siting of power plants. Even after companies experienced blackouts due to lightning damage to a transmission line, a plague of jellyfish, and so forth, no consideration was given to the prevention of severe accidents. During this phase, stakeholders did not develop a sense of crisis because Japan was spared any major earthquakes and tsunamis.

Initially, the media lauded nuclear power as a dream source of energy. Host communities welcomed the construction of nuclear power plants and took pride in their participation in a great national project. They signed safety agreements with utility companies while trusting the national government and utility companies in relation to the risks associated with these power plants. Anti-nuclear movements were instead associated with the ulterior motives of particular groups. In 1974, a radiation leak from the nuclear powered freighter Mutsu was given widespread media coverage. The resultant harmful rumors made the nuclear power sector nervous about disclosures, so companies in this sector. They withdrew into their own comfort zone.

\section{Phase 2: 1979-1996}

The robust industrial growth that Japan enjoyed due to the manufacture of home appliance, cars, equipment, and so forth was fueled by an abundant and high-quality workforce, as well as cheap oil. With productivity rising due to rationalization, scale-ups, and mass production, the Japanese economy had reached its heyday. In the 1980s, the property bubble encouraged speculative investments and ostentatious consumption. Black Monday in 1987 proved to be a prelude to the bursting of Japan's economic bubble. The Gulf War and the dissolution of the Soviet Union were then followed by the 1995 Great Hanshin earthquake.

By then, Japan had 50 nuclear power reactors, the third largest number in the world. The operation of multiple reactors at the same site complicated their management. The two oil shocks had prompted the Japanese government to promote nuclear power strategically. In the shadows behind the country's glorified construction projects, discussion of the faulty designs that had been used for old nuclear power plants was made taboo. Meanwhile, stakeholders rushed to deal with the many accidents that occurred, and problems were experienced both in Japan and abroad. The Three Mile Island Accident that occurred in 1979 revealed the risks 
associated with light-water reactors. In contrast to the obligatory installation of various emergency power generators in the United States, Japan failed to implement appropriate emergency response measures and preventive measures in a timely manner. Instead, it downplayed the risks involved by insisting that a meltdown in the event of an accident would only have a minor impact on the environment.

In response to the Chernobyl Accident seven years later, the Japanese nuclear sector conducted a public relations campaign to stress that the reactors and social regimes of the two countries differed. Meanwhile, Japan began to lag behind the West in terms of measures for responding to severe accidents. In pursuit of ever greater capacity utilization, almost no provisions were made other than repeated stopgap measures. The risk of major accidents was downplayed.

The regulatory authorities were also reluctant to revise their safety standards. In fact, many problems were left unresolved. Examples of this include the compromised independence of the regulatory authorities, the inadequate quality and number of personnel, the excessive dependence on independent institutions, the inadequate awareness of responsibilities, the formalized disaster response drills that lacked substance, and the performance of inspections that depended heavily on documentation. During Phase 2, nuclear power plants in Japan remained untouched by major natural disasters.

The host communities eventually became more interested in the introduction of a nuclear fuel tax and other economic benefits as they gradually became oblivious to the risks of nuclear accidents. These municipalities added staff and bolstered their advisory commissions, and they signed more broad-ranging safety agreements. The absence of a proper legal basis became an impediment to the management of nuclear power. An anti-nuclear lawsuit filed against the national government pressed the government and utility companies to insist on sufficient safety at old nuclear power plants, but fundamental discussions on nuclear safety became a taboo.

During this period, the outsourcing of maintenance became standard practice. As a result, multi-tiered structures began to form according to the business affiliations of the manufacturers and utility companies. Retired employees and local community members found jobs within this network. This outsourcing hollowed out the technical capacity of the utility companies, and personnel became less able to deal with problems on site. This shift gave rise to a stagnant corporate culture. The utility companies became increasingly dependent on manufacturers and experts for technical support. Similarly, the regulatory authorities became dependent on the utility companies, with inappropriate relations between the two becoming the established norm.

Politicians, governments, utility companies, manufacturers, concerned organizations, host municipalities, and local business circles formed a system that secured their vested interests. Meanwhile, universities became dependent on the nuclear industry for employment opportunities for their students and research funds. The nuclear power departments of the utility companies lost their original free spirit, and management became increasingly precarious because bottom-up views could no longer freely reach the top. Generational changes in engineers crippled the transfer of expertise concerning old nuclear power plants. Despite the economic recession, labor-management cooperation pushed up wages among the utility companies. Enjoying top-class compensation packages, employees showed an increasingly conservative tilt. The executives of regulatory authorities frequently changed and no training programs were conducted. They ended up responding to accidents without having conducted a serious review of the existing system and regulatory revisions. 


\section{Phase 3: 1997-2012}

The September 11 attacks shocked the world in 2001. A few years later, the financial crisis of 2008 triggered a global economic slowdown. Japanese economic growth stalled as China and other emerging economies began to close the gap on them. Rapid depopulation and ageing put both the national and local governments deeply in debt. After the Miyagi offshore earthquake and the Tokachi offshore earthquake, for the first time nuclear power plant in Japan was affected by the Niigata-Chuetsu offshore earthquake. In 1995, a sodium leak at the Monju reactor, which is managed by the Power Reactor and Nuclear Fuel Development Corporation (PNC), led to a scandal when the habitual covering up of problems was revealed. In 1999, the criticality accident that occurred at a nuclear fuel fabrication facility operated by JCO Co., Ltd. (JCO) caused deaths and forced the evacuation of local residents. The utility companies dismissed these problems as marginal accidents involving fuel production. Furthermore, they did not implement any measures for responding to severe accidents despite the criticality accidents that had already been experienced at nuclear power plants.

In 2002, repeated cover-ups, falsification and disguise incidents by the utility companies were uncovered. However, they avoided public criticism by replacing their top management while branding the problem as a safety culture matter. They did not attempt to investigate the root cause of the issue. Similarly, the regulatory authorities failed to deal with whistleblowing reports properly before the details were leaked. This blunder was inadequately investigated by the government and media.

A severe accident was barely avoided at the Mihama Nuclear Power Plant when its emergency core cooling system was activated and the piping for the secondary system of Unit 3 ruptured. Nonetheless, the regulatory authorities did not impose any regulatory requirements in terms of measures for responding to severe accidents. Instead, they simply encouraged the adoption of voluntary measures by power utilities. In 2007, the Kashiwazaki-Kariwa Nuclear Power Plant was affected by an earthquake. As a result, the power utilities focused their efforts on seismic reinforcement. Other than the decommissioning of two reactors at the Hamaoka Nuclear Power Plant, they failed to take adequate measures for tsunamis while stressing that the buildings at the Kashiwazaki-Kariwa plant had withstood ground motions twice as strong as expected. The power utilities made every effort to boost their flagging capacity utilization after a series of scandals and inadequate regulatory interventions. The National Institute of Advanced Industrial Science and Technology had warned of the risk that a tsunami comparable to the one triggered by the 869 Sanriku earthquake may occur. However, TEPCO procrastinated about the necessary response. The municipalities also failed to take any response as they were distracted by the idea of thermal neutron reactors fueled by plutonium. The national government and the utility companies did not incorporate any information on measures taken by other countries to address severe accidents. They were afraid of the potential impact on the ongoing anti-nuclear lawsuit, problems involving the provision of proper explanations to local communities, and a possible long-term shutdown. The idea of utilizing plutonium in thermal reactors emerged following the setback at the Monju reactor and the failure to complete a reprocessing plant. Spent fuel was subjected to interim storage.

The national government aspired to lead the world in the export of nuclear power plants to boost the country's energy security and curb global warming. It planned to encourage the gradual replacement of plants and drive the nuclear renaissance further. However, they neglected to take measures for responding to severe accidents and stem harmful practices in the nuclear sector. The host communities were heavily dependent on nuclear power plants for employment and other aspects of life. They were obsessed with the short-term benefits offered by additional reactors and the utilization of plutonium at thermal reactors. Due to concerns 
over global warming, nuclear power garnered unprecedented levels of public support.

No political efforts were made to address the issue of regulatory independence as pointed out by the IAEA. The regulatory authorities continued to rely on information from the utility companies, whose checks and balances were toothless at best. The utility companies formed cozy ties with their partner companies and local communities. The prevailing bureaucracy and blind observance of traditional approaches only favored vested interests. They gradually lost the ability to make radical changes to their policies. Furthermore, generational changes resulted in an inadequate transfer of technical skills to younger, less experienced engineers.

\section{Mechanism and Impact of Emergence of Each Issue}

Section I traced various factors behind the Fukushima Daiichi Nuclear Accident by reflecting on the history of nuclear power in Japan. Section II will look at these factors in terms of the issues involved to explain their emergence mechanism and impact.

\section{Formalities}

Formalities have constantly undermined nuclear safety. Disaster drills involving the local municipalities were simply performances that were choreographed according to the intended duration and availability of personnel. The media simply reported these events in a matter-offact way. Expecting such drills to raise awareness of potential hazards was unrealistic.

The Nuclear Safety Commission excluded risks associated with a long-term loss of external power without examining the on-site realities. Formal inspections, which were conducted by the regulatory authorities based mainly on documentation, overwhelmed the personnel in charge and endangered on-site safety.

After every accident, the leader of the host municipality would visit the nuclear plant to receive some media coverage as a performance for local residents.

The personnel working at the power plants did not even know how to operate the fire pumps, leaving the task to contractors instead. The operators had never undergone drills to cope with the potential loss of batteries and power supplies due to a tsunami. TEPCO took advantage of formalities to postpone any corrective actions based on the reasoning that the Japan Society of Civil Engineers had not officially recognized tsunami hazards. Formalities prevailed due to atrophied capacity, mannerisms, irresponsibility, complacency, lack of a sense of crisis, and prioritization of efficiency.

\section{Betrayal of the Three Principles}

Nuclear power has been advanced under a national policy led by bureaucrats and industrial circles, without the confirmation of public opinion. Nuclear power was never raised as an issue in national elections. This is contrary to the principle of democracy, which is one of the three principles for the peaceful use of nuclear energy. Moreover, nuclear power began with the use of imported technologies and regulations that imitated those used in the United States, which runs contrary to the principle of autonomy. Rather than following the principle of disclosure, the power utilities would cover up accidents while the regulatory authorities maintained a passive stance. Problems were usually revealed after the fact. Nuclear stakeholders had a shared sense of purpose in the development of this newfound energy for humankind. 
This purpose bred elitism and cozy ties. They covered up difficult problems or just put them off. In this way, they lost touch with the public. Under the national policy being carried out by private companies, the stakeholders protected their own convenience and interests while at the same time mortgaging the future.

From the very beginning, the pros and cons of nuclear energy have been debated by proponents and opponents who have refused to recognize each other's existence. They have never sat down at the same table, even to discuss nuclear safety scientifically. They have stuck to their own conclusions by employing reasoning and collecting evidence in problematic ways. Inconvenient information has been trivialized or shelved. Discussions have been conducted only among likeminded groups. Proponents of nuclear energy have dismissed opponents as they deemed engaging them in discussion to be a waste of time. Opponents have filed lawsuits against the national government and other proponents. Such developments have trapped proponents within a myth of nuclear safety that precludes the proposal of additional safety measures.

\section{Wrong Approach to Safety}

The Fukushima Daiichi Nuclear Accident proved that the conventional approach to safety was wrong. Japanese people tend to pursue peace of mind (reassurance) rather than actual safety, whereas science and technology should always be pursued based on the reality of the situation. Given our monetary and workforce constraints, hazards should be removed according to their risk level based on the principle of safety management. Visitors to the Chalon Plant, operated by Areva, are not required to wear helmets. In Japan, however, helmets must be worn at sites ranging from an office building all the way through to the main control room. Japanese people prefer to avoid complicating rules, so they think that everyone should share the inconvenience of wearing helmets. This type of thinking is typical of agricultural people. Japanese people tend to believe that if something happens once it is safe to assume that it happens all the time. They are very particular about working from the ground up with a focus on details. However, they seem to mistake these costly, unfocused, and lukewarm inconveniences as robust safety measures. The West has tight regulations for responding to severe accidents and allows the power utilities to conduct quality assurance activities of their own initiative. The approach taken by Japan is the complete opposite. Accidents should be prevented by identifying unsafe conditions and securing a budget for the necessary measures. In Japan, people felt safe by raising awareness with slogans such as "safety first" and "safety culture."

All safety measures leave some residual risk. Nonetheless, fastidious Japanese people left themselves vulnerable by refusing to acknowledge this fact. The government and utility companies feared that the disclosure of any residual risk would be tantamount to recognizing the hazards posed by nuclear power plants. The ensuing attacks from opponents of nuclear energy would complicate court cases involving safety reviews. They avoided discussing residual risk to save the trouble of having to provide explanations to municipalities about disaster drills. Major accidents in Japan and other countries were evaluated, but any logical association with the hazards posed by other nuclear power plants in Japan was avoided. For instance, instead of finding commonalities with the Three Mile Island Accident, the Chernobyl Accident, and the criticality accident that occurred at a JCO Plant, the nuclear sector stressed differences in terms of the equipment, social regimes, rules, and quality of personnel. Attention should have been paid to the possibility that a light-water reactor may experience a severe accident, fundamental faults in the monitoring systems for reactors, key points in relation to responding to accidents, the magnitude of damage caused by the environmental release of radioactivity, and 
the dangers posed by the blind pursuit of economic performance. Stakeholders also misinterpreted the probability of once in 10,000 years as meaning "never in our lifetime." They did not notice the danger of keeping three emergency power generators in the same place. Briefings to the public were simplified by consciously omitting any mention of exceptions and assumptions. Whistleblowers were shunned and a safety culture could not take root.

\section{Cozy Ties}

Stakeholders in the nuclear sector developed cozy ties amongst themselves, earning the nickname the "nuclear village." Their objective was to realize ensuring energy security by adopting nuclear technologies. Power utilities enjoyed a solid financial footing thanks to their regional monopolies, so they could offer benefits and profitable transactions to their desired targets. Cozy ties were formed mainly among politicians, bureaucrats, utility companies, and manufacturers. They also extended to financial institutions, academics, the media, municipalities, labor unions, fishery cooperatives, and other interest groups. Eventually, the nuclear village added securing the interests of its members as the second goal. To protect these cozy ties, its members sometimes behaved immorally and violated the rules while ignoring the laws of physics, lessons from the past, and warnings from insiders and outsiders. Insiders fell prey to inflexibility as bureaucracy and secrecy prevailed. Critical thinking was discouraged. The village could no longer clean itself up because it had excluded anyone who challenged or criticized the collective will. Undesirable information was distorted to suppress the sense of urgency or kept in-house. Even when a problem was revealed, the village prioritized protecting its own vested interests and pursuing self-preservation. Measures were gradually implemented based on precedence to avoid rocking the boat. Indeed, the head of the regulatory authority symbolically remarked that it is best to leave well enough alone in response to the suggestion that the Japanese disaster management system should be aligned with practices applied in other countries.

\section{Management Without Historical Perspective}

At TEPCO, the nuclear power department wielded power independently to influence business decisions. Directors represented the interests of their respective departments. Meanwhile, the board of directors failed to make unified company-wide decisions. Instead, it just rubberstamped what the departments wanted to do. Mr. Katsumata, the former chairman of TEPCO, explained in a press conference after the Fukushima Daiichi Nuclear Accident that they had adopted a management style of delegating tasks and responsibilities to the respective departments.

Responsibilities were also decentralized as TEPCO excessively outsourced the company's core assignments. Their technical capacity was hollowed out, with their internal and external monitoring sections having been disempowered. They became fixated on their existing policies, plans, and past circumstances. Any solutions to fundamental problems were pushed aside. The company simply tried to ride out such problems by exploiting the political influence based on their economic power.

TEPCO's top management should have had a firm historical perspective and been willing to rock the boat and break away from its prevailing inertia by squarely facing up to the series of problems that had arisen throughout the nuclear energy development. Top managers were chosen based on their ability to maintain the existing system and the policies of their predecessors. Radical reformers were excluded. Prime Minister Junichiro Koizumi publically 
avowed to smash the Liberal Democratic Party (LDP) in order to press ahead with postal reform. His historical perspective allowed him to predict correctly that the era of LDP-led majority governments, which had begun in 1955, would soon end. Upon his appointment as TEPCO president in 1993, Mr. Araki called for TEPCO to become a normal company with the aim of streamlining its management. However, he still failed to understand the historical background of the company's nuclear power department.

In France, the majority of the country's senior government officials and the top managers of major companies graduate from grandes écoles. Unlike the conveyor belt of students from Japanese universities as extensions of high schools, these selected few elites are trained to become well-rounded, cultured leaders who can consciously fulfill their vast potential for the benefit of society. Leaving aside its pros and cons, this traditional education system continues to produce the elites of French society. Japanese elites can tactfully assess a situation to avoid risks for their own organizations. They actively seek to expand their scope of authority, budgets, and staffing levels and secure plum jobs for their retirement. Utility companies indoctrinate their new employees to prioritize maintenance of the status quo. The factors that led to the Fukushima Daiichi Nuclear Accident demonstrate that nuclear energy was inadequately handled both by successive top management teams at TEPCO as well as bureaucrats from the Ministry of Economy, Trade and Industry and other government agencies that promoted nuclear energy as a national policy. They were only good at maintaining the status quo.

\section{Conclusions}

Society makes progress by learning from mistakes. We can learn lessons from the past only if we have a clear understanding of the reality of a situation. Such learning is also necessary to acquire an accurate understanding of issues that have been left unresolved and then stem potential problems resulting from past neglect. Japan can ill afford to continue using potentially hazardous nuclear energy if the measures that are taken in response to the Fukushima Daiichi Nuclear Accident are just stopgap ones that fail to address the root cause. New safety standards are being developed by the Nuclear Regulation Authority, but a more pressing task for our society is to build a solid foundation that will allow us to harness nuclear energy properly.

\section{General References}

1) Ryoichi Tobe et al.: The Essence of Failure-Japanese Military in Terms of Organizational Theory [in Japanese], Chuko Bunko.

2) Miwao Matsumoto: Structurally-Induced Disasters [in Japanese], Iwanami Shinsho.

3) Investigation Report [in Japanese], Independent Investigation Commission on the Fukushima Daiichi Nuclear Accident, Rebuild Japan Initiative Foundation.

4) NAIIC Report [in Japanese], National Diet of Japan Fukushima Nuclear Accident Independent Investigation Commission, Tokuma Shoten. 